\title{
Regeneration of Spent Catalyst and Impregnation of Catalyst by Supercritical Fluid
}

\author{
Farid M. Gumerov¹, Bernard Le Neindre², Timur R. Bilalov¹, Ajrat A. Sagdeev³ \\ ${ }^{1}$ Federal State Budgetary Educational Institution of Higher Professional Education "Kazan National Research Technological University", \\ Kazan, Russia \\ ${ }^{2}$ Université Paris 13, Sorbonne Paris Cité, Laboratoire des Sciences des Procédés et des Matériaux, CNRS, (UPR 3407), F-93430, \\ Villetaneuse, France \\ ${ }^{3}$ Federal State Educational Institution of Higher Professional Education Nizhnekamsk Chemical Technology Institute, Nizhnekamsk, \\ Russia \\ Email: gum@kstu.ru, Bernard.leneindre@lspm.cnrs.fr, t.bilalov@yandex.ru,sagdeev_aa@mail.ru
}

How to cite this paper: Gumerov, F.M., Neindre, B.L., Bilalov, T.R. and Sagdeev, A.A. (2016) Regeneration of Spent Catalyst and Impregnation of Catalyst by Supercritical Fluid. International Journal of Analytical Mass Spectrometry and Chromatography, 4, 51-65.

http://dx.doi.org/10.4236/ijamsc.2016.44006

Received: May 27, 2016

Accepted: December 5, 2016

Published: December 8, 2016

Copyright $\odot 2016$ by authors and Scientific Research Publishing Inc. This work is licensed under the Creative Commons Attribution-NonCommercial International License (CC BY-NC 4.0). http://creativecommons.org/licenses/by-nc/4.0/ (c) (i) (8) Open Access

\begin{abstract}
The possibility and feasibility of using supercritical fluid $\mathrm{CO}_{2}$ extraction process have been investigated and described in the book as part of the task of spent catalysts regeneration. The analysis of deactivating compounds has been carried out for industrial catalysts such as: 1) palladium catalyst G-58E of ethane-ethylene fraction hydrogenation; 2) nickel/kieselguhr catalyst of process of separating acetylenic compounds from isoprene; 3 ) active aluminum oxide catalyst of methyl phenyl carbinol dehydration process; 4) palladium catalyst LD-265 of hydrocarbons hydrogenation process; 5) nickel-molybdenum catalysts DN-3531 and Criterion 514 of kerosene hydrotreating process. The results of the study of catalyst deactivating compounds solubility in pure supercritical carbon dioxide and supercritical carbon dioxide are modified with polar additive. The results of the solubility study are described using the Peng-Robinson equation of state. The results of the implementation of the supercritical fluid $\mathrm{CO}_{2}$ extraction process with respect to deactivated industrial catalyst samples have been provided. A comparison of the characteristics of samples of catalysts regenerated using the traditional approach and the $\mathrm{SC}-\mathrm{CO}_{2}$ extraction process has been conducted. The possibility of using supercritical fluid $\mathrm{CO}_{2}$ impregnation process in the synthesis of a palladium catalyst has been investigated. The synthesis of palladium chloride-based organometallic complexes has been carried out. The results of the study of solubility thereof in supercritical carbon dioxide have been provided. A dynamic supercritical fluid $\mathrm{CO}_{2}$ impregnation process condition has been implemented. A comparison of the characteristics of palladium catalyst samples synthesized using the conventional approach and $\mathrm{SC}-\mathrm{CO}_{2}$ impregnation process has been conducted and presented in the book.
\end{abstract}




\section{Keywords}

Palladium Catalyst G-58E, Nickel/Kieselguhr/Diatomite Catalyst, Active Aluminum Oxide Catalyst Palladium Catalyst LD-265, Nickel-Molybdenum Catalysts DN-3531 and Criterion 514, Catalyst Regeneration, Catalyst Activity, Benzonitrile Complex of Palladium Chloride, Styrene Complex of Palladium Chloride, Cyclohexene Complex of Palladium Chloride

\section{Introduction}

In recent years, the chemical and oil industries are undergoing their most serious challenge technically, economically and environmentally, as new processes are gradually being introduced in many markets. These industrial changes come from a greater need for productivity and economic improvement.

Most industrial processes would not be feasible without catalysts, so it is particularly important to understand all the factors that determine the catalytic properties. Large amounts of catalysts are used in the petroleum refining and petrochemical industry to upgrade the different flows of petroleum and residues, and the usual production of gasoline, diesel fuels, jet fuels, heavy oil hydrocarbons, petrochemicals and plastics. In addition, with the rapid development and wide application of catalysis technology, more and more sophisticated catalysts are introduced in refining and petrochemical applications, to increase the catalytic performance. This leads to manage refining and petrochemical units differently.

A catalyst is a material of constant composition (gas, liquid, or solid), that increases the rate of a chemical reaction by providing an appropriate reaction pathway, with the lowest activation energy. As the activation energy is lower, more reaction products will be formed in the same period. Heterogeneous catalysis differed from homogeneous catalysis in the number of phases present during the reaction. The heterogeneous catalysis is a surface phenomenon, wherein the catalyst phase, solid mostly, differs from that of the reactants.

After periods of operation, the catalysts undergo mechanical, physical and chemical changes with a consequent rapid loss in activity and often in selectivity. In chemical processes, the progressive deactivation of solid catalysts is a major economic concern and the control of their stability, activity and selectivity has become crucial. For these reasons, there is a strong motivation to understand the mechanisms leading to any loss in activity and/or selectivity and to find out the efficient preventive measures and regenerative solutions that open the way to cheaper and cleaner processes [1].

\section{Catalyst Sinthesis and Regeneration}

Most of the catalysts used in the refining or petrochemical applications deactivate quickly with time. The time scales for the deactivation catalyst vary considerably with the process, and has profound consequences for process design. The design of fixed bed 
catalytic reactors is based on the kinetics of deactivation of the catalyst, so that the catalyst life is at least six months and typically several years. This decrease in activity can be compensated by changing some operating parameters. However, at some point, catalyst replacement is inevitable.

Catalyst deactivation is a complex phenomenon, generally defined as the loss of catalytic activity and selectivity over time. Catalyst deactivation is attributed to changes in the structure and state of the catalyst, due to the interaction between the catalyst and the impurities present in the feed stream, wherein the catalyst is used. It is a problem of great and ongoing concern in the practice of industrial catalytic processes. The costs to industry for catalyst replacement and process shutdown amount to billions of dollars per year.

The main causes of deactivation of solid catalysts and their mechanisms were reviewed s by Bartholomew [2]. The causes of deactivation can be grouped into five types [2] [3] [4] [5]: 1) Poisoning by strong chemisorption of species; 2) Formation of deposits on the catalyst; 3) Chemical and structural alterations of the catalysts; 4) Mechanical alterations; 5) Leaching of active species. In commercial processes, catalyst deactivation is often due to several of these causes with interdependent effects [2] [3] [4] [5].

The activity of the catalyst gradually declines due, mainly, to the building-up of coke which plays a crucial role in the operation of the reformer under industrial conditions. There are numerous reactions and mechanisms of coke formation, depending on the nature of the catalyst, whether it is a pure metal, or contains additional non-metallic elements to increase the selectivity [2]. The coke formation is strongly dependent on temperature and feedstocks. Refinery feedstocks, in general, are extremely complicated chemical mixtures in which each heteroatom is present in the form of literally hundreds of different compounds [6].

Much of the coke formation arises due to carbon molecules adsorbed on the surface of the metal compound to form multiple layers, covering the active sites of the surface of the heterogeneous catalyst, therefore, decreasing the active surface area of the catalyst and reducing its yield and selectivity. In certain circumstances when carbon compounds become trapped in the pores, they can cause unusual stress increase within the pore, which can break the catalyst [2].

In addition, the metal oxide catalysts contain acidic pore spaces that affect the coke formation. These acidic pores modify the behavior of carbon atoms in the cyclic and aromatic chains, which link with carbon radicals, to form high molecular weight compounds that stick to catalysts and are difficult to remove.

Coke formation is believed to result from cracking and polymerization reactions; perhaps from the deposition of coke precursors such as anthracene, coronene, ovalene and other condensed ring aromatic molecules on the catalyst, these polymerizing to form coke [7]. It is possible to recover a large part of the initial catalytic activity when the deactivation is reversible (such as coke fouling). During operation, the temperature of the process is gradually raised to compensate for the activity loss caused by coke deposition. Eventually, however, economics dictates the necessity of reactivating the cata- 
lyst. Consequently, in all processes of this type the catalyst must necessarily be periodically regenerated by removal of the coke from the catalyst [7].

Coke removal by oxidation is a difficult task and requires a careful control of the temperature. Typically, in the regeneration, the coke is burned from the catalyst at controlled conditions. In a regeneration of this type, the catalyst is contacted with oxygen at flame front temperatures ranging about $700 \mathrm{~K}$ to about $850 \mathrm{~K}$, this being generally followed by a secondary burn with increased oxygen concentrations as coke is depleted from the catalyst [7]. The reaction is highly exothermic and can result in overheating and sample thermal reorganization. The result is the loss of surface area (sintering) and the formation of refractory compounds. Coke has also been removed from catalysts by contact with hydrogen at elevated temperature.

Deactivation by poisoning involves chemisorption on the active sites of the competing poison molecules with reactive molecules [6]. Poisoning occurs when there is a loss of catalytic activity due to substances that interact strongly and irreversibly with the active sites of the catalyst. The most common impurities found in the feed streams are sulfur, phosphorus, zinc, calcium, arsenic, alkali metals, heavy metals, iron, and chlorides present in gaseous form or as micron size particles. Since these substances accumulate on the surface of catalysts, they are in competition with other impurities for space on the surface area of catalysts. In addition to physically blocking adsorption sites, adsorbed poisons may induce changes in the electronic or geometric structure of the surface [8].

Sintering generally refers to a structural modification of the active surface of the catalyst due to high temperature and/or pressure. Sintering occurs either due to metal atoms, which migrate from one crystallite to another, through the surface or in the gas phase, by reducing the small crystallite size and increasing the larger ones, or by migration of the crystallites along the surface, followed by collision and coalescence of two crystallites [8] [9]. It should be noted that the sintering rate increases exponentially with temperature and becomes more and more pronounced above temperatures of 900 K.

Catalyst regeneration involves the processing of spent catalysts to make them reusable. This is done by restoring the chemical properties of spent catalysts and thus restoring their efficiency through a process called regeneration of catalyst [10]. There are several reasons for regeneration. Initially, the reasons were economic, while later awareness was brought about by environmental concerns about disposals [11]. The main advantage of catalyst regeneration is that it costs less than fresh catalysts [10].

If a catalyst has been deactivated by the surface deposition of a foreign substance or by the incorporation of a removable poison, it may be possible to regenerate the catalyst and restore the catalytic activity [12]. Regeneration of deactivated catalysts is possible for most of catalytic processes and is widely practiced. The main purpose is to eliminate the temporary poisons on the catalyst surface and restore the free adsorption sites [13]. If the regeneration is technically possible, it is the preferred option for the environment and economically to face the spent catalysts; it facilitates prolonged use of the catalyst, 
minimizing the use of new raw materials and reduces the need for definitive recovery of disposal [12].

Along with the rapid development and wide application of catalysis technology, the amounts of different spent catalysts are increased from year to year [14]. In addition, catalysts have thus become more and more sophisticated and one indirect consequence is that they need more careful procedures for regeneration than in the past.

Depending primarily on the chemical and structural changes in the catalyst during use, the user is faced with several options for dealing with the spent material [12]. Several methods such as disposal in landfills, recovery of some or all the components in the material, use of the material in another process, reuse of the material by regeneration and rejuvenation and utilization as raw materials to produce other useful products are available for the users, which deal with the spent catalyst problem. The choice between these options depends on technical feasibility and economic consideration [15].

Disposal of a spent catalyst landfill is always the least environmentally preferred option, and is an option that requires compliance with stringent environmental regulations [12]. Safe disposal of a spent catalyst is a major environmental problem, as landfill disposal is no longer generally accepted as the best practice. Environmental laws concerning spent catalyst disposal have becomes increasingly more severe in recent years [16]. Landfill does not remove or destroy any hazardous materials which, if the threats are not properly managed, can pose long term health and environmental risks, and be affected by future regulatory changes [12]. In many countries, the spent catalysts have been classified as hazardous waste material and are subject to strict guidelines for disposal. Most major refinery companies have set up special disposal practices and enable authorized waste collectors and processors to dispose the catalyst waste [17].

In the USA, the current regulations of the Resource Conservation and Recovery Act (RCRA) require landfill to be built with double liners and with leachate collection and groundwater monitoring facilities. Thus, the landfill option is more expensive today. In addition, it carries with it a continuous environmental responsibility for the life of the dumb-site. Treatment prior to filling of the land may be necessary in some cases, which further increases the cost [16].

Catalysts that can be regenerated are usually able to be used through several operation regeneration cycles. It is important to note that in the case of regeneration of spent catalyst, the product often does not change the ownership, and that its original economic value is fully recovered and exploitable [12].

The spent catalysts are generally treated as harmless industrial waste, but their characteristics are varied in different processes and condition [14]. If the spent catalysts can be regenerated and activated effectively, they can be reused with higher values and economic efficiency [14].

The physical properties of spent catalysts, as well as their composition, are generally different from those of fresh catalysts. For example, spent hydrotreating catalysts contain metal sulfides and coke and may have additional contaminants that were not present in the fresh catalyst [18]. 
The catalyst regeneration market is divided into two regeneration technologies: offsite and on-site. Both regeneration technologies have specific requirements of catalyst regeneration, such as refinery, chemicals, and petrochemicals which differ in cost and efficiency [19]. In the off-site (ex-situ) regeneration, the catalyst is discharged from the reactor. The on-site (in-situ) regeneration does not require removal of the catalyst from a reactor. Generally, the procedure is to burn off, or oxygenate, the temporary poisons, such as green oil, in order to resume the activity of the catalyst. Regeneration of the catalyst may be accomplished, for example, by heating the catalyst in air to a temperature over $573 \mathrm{~K}$ up to about $773 \mathrm{~K}$, to incinerate any organic material, polymers, or char [13].

The off-site catalyst regeneration has the highest market share and is also the fastest dynamic market. Off-site regeneration is a fast-growing technology chosen by the petroleum refining and chemical and petrochemical industries because of strict environmental regulations, cost optimization, and better quality and performance of regenerated catalysts [19].

The price of the regeneration of the catalyst is lower than that of fresh catalysts which governs the overall market growth. Prices also depend on the methods used, as on and off-site regeneration. The market for regenerated catalyst, in terms of value, is estimated to reach $\$ 5$ billion by 2019 , with a compound annual growth rate (CAGR) of 5.54\% between 2014 and 2019. Due to the closure of few refineries in Europe, the regenerated catalyst market will undergo a slow growth rate. In North America, the catalyst regeneration market is expected to grow quickly in the next years due to the processing of shale gas. In Asia-Pacific, the catalyst regeneration market is forecast to grow at the highest CAGR between 2014 and 2019 due to rise in refinery capacity [19].

Many spent catalysts contain sufficient concentrations of precious metal based constituents, or other materials, to be economically worth recovering; and the recovery of the precious metals from spent catalysts, by metallurgy processes or direct reuse as the construction materials, has been well established for many years [16]. The cost of commercial cobalt, nickel, and molybdenum based catalysts has increased by a factor of four over the last five years. This has produced a strong economic incentive to regenerate used LC-Fining catalysts. The recovery of metals not only reduces the amount of wastes for disposal but also preserves natural resources, then offers an environmentally reliable alternative to landfill disposal [19].

Fluctuations in the market prices of the recovered metals and their purity significantly influence the economics of the metal recovery process, making it less attractive for spent catalysts that contain low level of metals. However, in recent years, the emphasis has been placed on the development of processes for recycling spent catalysts that contain high concentrations of precious metals [20] [21] [22] [23].

Many variant of the same type of regeneration process are found in the industry, and the operating conditions can be quite diverse, depending on the type of catalyst used and the feedstock processed [24].

The spent catalysts can be regenerated or reactivated by different physical, chemical 
and thermal methods [25]. The advantages in terms of energy savings or environment, associated with these recycling activities are also very important. It has been estimated that the recycling of various metal scraps consumes about $33 \%$ less energy, and generates $60 \%$ less harmful wastes than the production of fresh catalysts from ore [17].

In the 1970s, most refiners regenerated their catalysts in-situ, in fixed-bed reactors, as it was considered that in-situ regeneration was more practical and attractive [26]. As a matter of fact, the ex-site regeneration delays the continuous operation of industrial processes, as the catalysis reactors and processes must be stopped for the dismantling of deactivated catalysts and transport them to the regeneration plant [25]. However, temperature gradients and hot spots can take place in in-situ regeneration, resulting in sintering of the catalyst and the loss of activity. Another problem is that catalyst fines remain in the catalyst bed, which can cause fouling of the reactor and pressure drop when the reactor is restarted [26].

In-situ regeneration and sulfiding of catalysts in the refinery increase the emissions of harmful gases from refinery site, like the production of large excess of hydrogen sulfide. Oxidative regeneration of catalyst is carried out by heating or injection of hot steam, hydrogen, oxygen, and various oxidizing agents, reducing agents, or organic solvents, in the catalysis reactor, for coke burning, thus generating $\mathrm{CO}, \mathrm{CO}_{2}, \mathrm{NO}_{\mathrm{x}}$ and $\mathrm{SO}_{\mathrm{x}}$ where $\mathrm{x}$ takes values from 1 to 3 , which accumulate in the gas system of the reactor. Each of these gases must be treated in downstream process units, to reduce pollution from the refinery [25].

In addition, there are few studies investigating the regeneration efficiency of different methods and catalysts, and the effects of various operation conditions in the in-situ regeneration of the deactivated catalysts [25].

Today, the major refining companies are largely practicing catalyst reuse, and have abandoned in situ regeneration for different reasons, one being that it took too much downtime without production, and are encouraging actions which minimize shut down time.

EX-situ regeneration is a booming technology selected by oil refining and chemical and petrochemical industries, because of strict environmental regulations, cost optimization, and better quality and performance of the regenerated catalysts [19]. Today, 90 to $95 \%$ of the catalyst regenerated in the U.S. and in Europe is regenerated ex situ [26]. The off-site catalyst regeneration has the highest market share and is also the fastest growing market [19].

$E_{X}$-situ regeneration has several advantages over in-situ regeneration [26]. EX-situ regeneration of catalysts results in better recovery of activity due to close control of the regeneration temperature, a better evaluation of the catalyst for reuse, through a variety of tests for characterization and quality control, and a chance to remove fines and chips that contribute to pressure drop problems [27]. The safety of the environment and the reduction of delays of shutdown and startup of units, are the additional benefits of ex-situ regeneration, because the in-situ regeneration is longer and more difficult to control. In-situ regeneration recovered only $50 \%$ to $60 \%$ of the catalyst activity, while 
ex-situ regeneration retrieves $75 \%$ to $95 \%$ [26].

The chemical treatment is one of the popular methods of regeneration of spent catalysts. Various acidic or alkaline solutions have been used to regenerate the spent catalysts, such as oxalic acid, $\mathrm{HCl}, \mathrm{HNO}_{3}, \mathrm{NaOH}, \mathrm{H}_{2} \mathrm{SO}_{4}, \mathrm{VOSO}_{4},\left(\mathrm{NH}_{4}\right)_{2} \mathrm{WO}_{4}$, acetic acid, and citric acid. The main function of these solutions in catalyst regeneration is to remove the blocked carbons or poisoned residues from the spent catalysts. The effects of various chemical reagents, concentrations, and operating conditions on catalyst regeneration vary with different spent catalysts (active metals and compositions) [14] [19].

Oil refining and petrochemical plants are currently undergoing serious challenges from a technical and economical point of view, as well as from an environmental point of view [28].

This document will provide a brief overview of the management practices and regeneration of spent catalysts, with the focus on the technologies, issues and opportunities related to the preservation of the environment [17].

The spent catalysts which were regenerate in this study, are commercial catalysts unloaded from different type of industrial units, developed by Nizhnekamsk Chemical Industries, Nizhnekamsk, Russia. Most of the data presented here were obtained in the laboratories of Kazan National Research Technological University, in Russia.

The analysis of deactivated compounds was carried out for industrial catalysts such as: 1) G-58E grade palladium for the selective hydrogenation of ethane-ethylene; 2) nickel-on-kieselguhr for the separation of acetylene compounds from isoprene; 3) "active aluminum oxide" for methyl phenyl carbinol dehydration process; 4) LD-265 grade palladium for the hydrogenation process of hydrocarbon; 5) Dn-3531 and Criterion 514 , nickel-molybdenum grades for hydrotreatment of kerosene and gas oil. In most refineries, most spent catalyst waste comes from the residue of hydrotreating and hydroprocessing units. This is because the catalysts used in these processes deactivate rapidly by coke and metal (Mo and $\mathrm{Ni}$ ) deposits, and have a short life [29].

Another important subject present in this volume is the measurement of solubility of compounds extracted from deactivated catalysts.

The solubility of deactivated catalyst compounds was carried out in pure supercritical carbon dioxide and supercritical carbon dioxide modified with polar co-solvents. $\mathrm{CO}_{2}$ is a non-polar solvent that can be used in liquid or supercritical states. Liquid $\mathrm{CO}_{2}$ is significantly less polar solvent than supercritical $\mathrm{CO}_{2}$, and is limited to the extraction of small non-polar molecules. The solubility was described using the Peng-Robinson equation state.

Now, for industrial applications, sub and supercritical fluids can be considered as the most promising innovative technologies. Supercritical fluids combined the advantages of both gaseous and liquid properties. They greatly intensify heat and mass transfer processes as the thermal conductivity and the specific heat at constant pressure, diverge near the critical point. If we consider the kinematic viscosity $(v=\eta / \rho)$, supercritical fluids have values which are one to two orders of magnitude lower than the classical liquid organic solvents. As the kinematic viscosity is presented in the denominators of 
Grashof and Reynolds numbers, its produces a significant increase of the degrees of freedom and forced convection in SCF media. The diffusivity (binary diffusion, self-diffusion) of supercritical fluid media is one to two orders of magnitude higher than the one of liquid organic solvents. Supercritical fluid media have no phase boundary, no surface tension, and therefore no capillary effect; then they show high degree of penetration into the porous structures. Moreover, the residues are easy to recover and the extractant can be recycled. With their original properties, we believe than supercritical fluids provide significant opportunities for the synthesis and regeneration of heterogeneous catalysts. The success of this approach has been confirmed not only by numerous studies but also by many industrial achievements.

The key parameter to be analyzed in this innovative process is the solubility of deactivated compounds of catalyst in SCF media, related to their chemical composition. The three main factors that govern the solubility of a substance in each solvent are the nature of the solute and solvent, their states of aggregation and the thermodynamic conditions. Two opposite trends control the nature of ongoing modifications of the solubility of the substance in a supercritical fluid solvent. On the one hand, the elevation of the temperature increases the vapor pressure of the solute and thereby its concentration in the solvent phase increases. Therefore, there is also an increase in solubility. On the other hand, an increase in temperature (at $\mathrm{P}=$ constant) produces a decrease of the density of the supercritical fluid and a reduction of its dissolving capacity.

The solubility of substances in supercritical fluid was the subject of intense researches over the last 2 - 3 decades [30] [31] [32] [33] [34]. They included the development of new experimental methods and techniques to study this thermodynamic property [35].

The solubility is a property of great practical importance in supercritical fluid media. However, the implementation of new technologies based on SFC in the industry has been very slow. One reason for this is probably due to the lack of researches on phase equilibrium characteristics, especially of multi-component systems in supercritical fluid; the other is related to the absence of significant developments of modeling steps, simulation and optimization of processes and technology in general.

Specific heat measurements of some compounds have also been reported, they are used to determine the amount of heat, which may be necessary for the system during the regeneration process, when it is carried out in an industrial plant. This information is necessary for the equipment design to the industrial scale.

However, we must acknowledge that the supercritical carbon dioxide extraction process and impregnation processes by supercritical carbon dioxide, which are already in operation on a commercial scale, met the industrial requirements for a perfect regeneration and synthesis of heterogeneous catalysts.

This book is an overview of processes and operations involved in the regeneration of catalysts by pure supercritical fluids and supercritical fluids associated with co-solvents. The objective here is to provide the basic information to regenerate spend catalysts by new processes that respect the environment.

The scientific bases of the adsorbent and catalyst regeneration by supercritical fluid 
extraction were developed a long time ago. However, there is little information, about the industrial implementation of this process in relation to certain types of catalyst systems. Nevertheless, it is obvious that due to the wide variety of catalyst systems used in the industry, it is not possible to establish a universal guide of regeneration technology. This in turn implies the need of a preliminary study of almost every new process. This paper presents the results of the study of the process of regeneration of catalysts such as: palladium catalyst G-58E, nickel on kieselguhr/diatomite catalysts, active aluminum oxide, LD-265, a mixture of catalysts Dn-3531 and Criterion 514.

This book gathered a series of studies [36] [37] [38] [39] describing new methods for the regeneration of heterogeneous catalysts for important industrial chemical processes. In this book, we have proposed new extraction techniques using supercritical fluid extraction (SFC), which seems to be one of the most promising as a green reaction medium. The feasibility of using supercritical fluid $\mathrm{CO}_{2}$ extraction process was investigated for spent catalysts regeneration. The low regeneration temperature of supercritical carbon dioxide eliminates the risk of thermal deterioration of the catalyst, namely the collapse of the pores, prevents the reduction of the surface area and the sintering, and allows regeneration of catalysts to their maximum possible activity.

The book consists of six chapters. Chapter 1 is devoted to the process of supercritical regeneration of palladium catalysts G-58E used in the hydrogenation process of ethane-ethylene fraction is analyzed. The chapter describes the nature of deactivating deposits forming on the catalysts, solubility of deposits like anthracene, that was measured in supercritical carbon dioxide at temperatures 313 and $323 \mathrm{~K}$ and pressures from 10 to $35 \mathrm{MPa}$. The regeneration of deactivated catalysts was performed in supercritical carbon dioxide at various process conditions, within the temperature range from 313 to $423 \mathrm{~K}$ and pressures 20 and $40 \mathrm{MPa}$. A comparison of specific surface areas and activities of freshly prepared and regenerated catalysts with supercritical carbon dioxide samples showed that the proposed method was very competitive compared with the traditional regeneration techniques. In addition, the solubility of benzonitrile, styrene and cyclohexene complexes of palladium chloride in supercritical carbon dioxide were measured in the temperature range from 308 to $323 \mathrm{~K}$ and pressures from 10 to 32.5 $\mathrm{MPa}$. Results were described with the Peng-Robinson equation of state.

Chapter 2 is devoted to the process of supercritical regeneration of nickel on kieselguhr/diatomite catalyst, used during hydration of unsaturated compounds. The chapter describes the possibility of regeneration of the catalyst using pure supercritical carbon dioxide and $\mathrm{SC}-\mathrm{CO}_{2}$ modified with polar additive ( $3 \mathrm{wt} \%$ methanol) at 343 and $423 \mathrm{~K}$, in the pressure range $10-30 \mathrm{MPa}$. The kinetic features of the regeneration of the catalyst with $\mathrm{SC}-\mathrm{CO}_{2}$ are studied. A comparison of activities of freshly prepared, spent and regenerated with $\mathrm{SC}-\mathrm{CO}_{2}$ catalyst samples, showed that the method suggested was highly competitive compared to conventional regeneration techniques.

Chapter 3 is devoted to the process of supercritical regeneration of active aluminum oxide catalyst, used in the methyl phenyl carbinol dehydration process. The chapter describes the nature of deactivating deposits that are formed on the catalyst, solubility 
of one of them: styrene, that was measured in supercritical carbon dioxide in the temperature range from 323 to $333 \mathrm{~K}$ and the pressure range from 12 to $24 \mathrm{MPa}$. Results have been described with using the Peng-Robinson equation of state. The possibility of regeneration of the catalyst using pure supercritical carbon dioxide, and supercritical carbon dioxide modified with polar additive is investigated at $423 \mathrm{~K}$, in the pressure range $10-30 \mathrm{MPa}$. The kinetic of regeneration of the catalyst with $\mathrm{SC}-\mathrm{CO}_{2}$ was studied. A comparison of activities of freshly prepared, traditionally regenerated, and regenerated with $\mathrm{SC}-\mathrm{CO}_{2}$ catalyst samples, showed that the proposed method is very competitive compared with the conventional regeneration techniques.

Chapter 4 is devoted to the process of supercritical regeneration of the LD-265 palladium catalyst used in the hydrogenation of diene hydrocarbons is analyzed. The chapter describes the nature of deactivating deposits formed on the catalyst, solubility of one of them: polyisoprene that was measured in supercritical carbon dioxide in the temperature range from 343 to $393 \mathrm{~K}$ and pressures from 20 to $34 \mathrm{MPa}$. Heat capacity and enthalpy of mixing of polyisoprene in supercritical carbon dioxide was also measured in this work. The possibility of regeneration of the catalyst using pure supercritical carbon dioxide and supercritical carbon dioxide modified by polar additive is investigated at 343 and $423 \mathrm{~K}$, in the pressure range $10-30 \mathrm{MPa}$. The kinetic of the catalyst regeneration with $\mathrm{SC}-\mathrm{CO}_{2}$ was studied. A comparison of the activities of traditionally regenerated and regenerated with $\mathrm{SC}-\mathrm{CO}_{2}$ catalyst samples showed that the method suggested is very competitive compared to traditional regeneration techniques.

Chapter 5 is devoted to the process of supercritical regeneration of DN-3531 and Criterion 514 nickel-molybdenum catalysts used in the hydrotreating processes of kerosene and gas oil. The chapter describes the nature of deactivating deposits formed on the catalysts, solubility of one of these them: anthracene that was measured in supercritical carbon dioxide at temperatures of $308 \mathrm{~K}$ and at pressures from 10 to $30 \mathrm{MPa}$ in association with the researches done previously. The results of solubility were described using the Peng-Robinson equation of state. The regeneration of deactivated catalysts in pure supercritical carbon dioxide and supercritical carbon dioxide modified with polar additive was studied in varying process conditions in the temperature range from $323 \mathrm{~K}$ to $383 \mathrm{~K}$ and pressures from 10 to $30 \mathrm{MPa}$. A comparison of the specific surface areas and thermal analysis of spent and regenerated catalyst samples with supercritical $\mathrm{CO}_{2}$ showed that the method suggested was very competitive compared to conventional regeneration techniques.

Chapter 6 is devoted to the results of the research process on the methods of impregnation using supercritical $\mathrm{CO}_{2}$ in static and dynamic modes, to synthesize a palladium catalyst. The kinetics of the process is determined in the pressure range from 15.0 to $35.0 \mathrm{MPa}$, for temperatures of $308.15 \mathrm{~K}, 313.15 \mathrm{~K}, 318.15 \mathrm{~K}, 323.15 \mathrm{~K}, 328.15 \mathrm{~K}$ and $333.15 \mathrm{~K}$. The results of the working conditions, and the activity measurements of the sample surface of the catalyst synthesized by impregnation of an aluminum oxide support, with supercritical carbon dioxide suggests that this approach is competitive with traditional impregnation methods. A comparison of the characteristics of the palladium 
catalyst samples synthesized by the approach of the impregnation process and conventional SC- $\mathrm{CO}_{2}$ is reported.

The data obtained suggest that the regeneration using supercritical carbon dioxide modified with various polar additives allows to almost a complete restoring of the performance of these various types of catalysts. In this case, the regeneration is carried out at significantly lower temperatures than against the methods of regeneration generally used, which has a positive effect on the overall performance of catalysts and on the energy consumption, associated with the regeneration thereof, which ultimately leads to lower cost of the ended products.

Per some estimates, the use of supercritical fluid $\mathrm{CO}_{2}$ extraction process in the catalyst regeneration provides two-fold energy efficiency and a larger number of possible regeneration cycles. The unique properties of the solvents in the supercritical fluid state also allow the execution of tasks of application of catalyst active components, that we have illustrated by the example of synthesis of a palladium catalyst, like G-58E catalyst. The samples obtained using supercritical carbon dioxide are of the same quality as the fresh catalysts prepared by the manufacturers.

\section{Conclusions}

This paper describes a new process for the complete recovery of resource that is simple, effective, economical and environmentally friendly. Today, there is a higher awareness for a sustainable society, a growing concern about the effects of greenhouse gas; the fact that the demand for the production of clean petroleum is rising, implies a business opportunity and an increased market interest for renewable raw materials and processes, and for the long term survival of companies. Research on the development of processes for minimization and recycling of spent catalyst wastes has received increasing attention in recent years because of their hazardous nature and stringent environmental regulations on their disposal. In this paper, various methods used for spent catalyst waste reduction at source and the processes available for their recycling and reuse are reviewed.

The scientific bases of the adsorbent and catalyst regeneration by supercritical fluid extraction were developed a long time ago. However, there is little information, about the industrial implementation of this process in relation to certain types of catalyst systems. Nevertheless, it is obvious that due to the wide variety of catalyst systems used in the industry, it is not possible to establish a universal guide of regeneration technology. This in turn implies the need of a preliminary study of almost every new process. This paper presents the results of the study of the process of regeneration of catalysts such as: palladium catalyst G-58E, nickel on kieselguhr catalysts, active aluminum oxide, LD-265, a mixture of catalysts Dn-3531 and Criterion 514. The data obtained suggest that the regeneration using supercritical carbon dioxide modified with various polar additives allows to almost a complete restoring of the performance of these various types of catalysts. In this case, the regeneration is carried out at significantly lower temperatures than against the methods of regeneration generally used, which has a pos- 
itive effect on the overall performance of catalysts and on the energy consumption, associated with the regeneration thereof, which ultimately leads to lower cost of the ended products. Per some estimates, the use of supercritical fluid $\mathrm{CO}_{2}$ extraction process in the catalyst regeneration provides two-fold energy efficiency and a larger number of possible regeneration cycles. The unique properties of the solvents in the supercritical fluid state also allow the execution of tasks of application of catalyst active components, that we have illustrated by the example of synthesis of a palladium catalyst, like G-58E catalyst. The samples obtained using supercritical carbon dioxide are of the same quality as the fresh catalysts prepared by the manufacturers.

This monograph also describes the results of the study of important thermodynamic characteristics of the systems involved in the catalyst production and regeneration processes, which include, first and foremost information on the solubility of the precursors of active catalyst components and catalyst deactivating compounds in supercritical fluid solvents. These particular data largely determine the conditions of catalyst regeneration and synthesis processes that are optimal, from the viewpoints of energy and resource saving.

\section{Acknowledgements}

The authors of this study are grateful to the Russian Science Foundation (RSF) for financial support in the form of the respective grant (contract No. 14-19-00749).

\section{References}

[1] Guisnet, M., Ribeiro, F.R. and Guisnet, M. (2011) Deactivation and Regeneration of Zeolite Catalysts. Imperial College Press, Singapore, World Scientific [Distributor], London, 340 p.

[2] Bartholomew, C.H. (2001) Mechanisms of Catalyst Deactivation. Applied Catalysis A: General, 212, 17-60. https://doi.org/10.1016/S0926-860X(00)00843-7

[3] Lassi, U. (2003) Deactivation Correlations of Pd/Rh Three-Way Catalysts Designed for Euro IV Emission Limits: Effect of Ageing Atmosphere, Temperature and Time. http://herkules.oulu.fi/isbn9514269543/html/x546.html

[4] Ertl, G., Knozinger, H., Weitkamp, J. and Trimm, D.L. (1997) Handbook of Heterogeneous Catalysis. Wiley-VCH, Weinheim, 3, 1263 p.

[5] Deutschmann, O., Knözinger, H., Kochloefl, K. and Turek, T. (2009) Heterogeneous Catalysis and Solid Catalysts. Ullmann's Encyclopedia of Industrial Chemistry. Published Online: 15 April 2009.

[6] Sánchez-Delgado, R.A. (2002) Organometallic Modeling of the Hydrodesulfurization and Hydrodenitrogenation Reactions. Springer Science \& Business Media, New York, 209 p. https://doi.org/10.1007/0-306-47619-3

[7] Baird Jr., W.C., Eberly Jr., P.E. and Balinsky, G.J. (1984) A Catalyst Regeneration in a Catalytic Reforming Process. US Patent No. US 4440667.

https://www.google.ch/patents/US4440667

[8] Trimm, D.L. (2001) The Regeneration or Disposal of Deactivated Heterogeneous Catalysts, Applied Catalysis A: General, 212, 153-160. https://doi.org/10.1016/S0926-860X(00)00852-8

[9] Forzatti, P. and Lietti, L. (1999) Catalyst Deactivation. Catalysis Today, 52, 165-181. 
https://doi.org/10.1016/S0920-5861(99)00074-7

[10] Gumerov, F.M., Le Neindre, B., Bilalov, T.R., et al. (2016) Regeneration of Spent Catalyst and Impregnation of Catalyst by Supercritical Fluid. Nova Publisher, New York, 168 p.

[11] Subramanian, B., Christou, S.Y., Efstathiou, A.M., Namboodiri, V. and Dionysiou, D.D., (2010) Regeneration of Three-Way Automobile Catalysts Using Biodegradable Metal Chelating Agent-S, S-ethylenediamine Disuccinic Acid (S, S-EDDS). Journal of Hazardous Materials, 186, 999-1006. https://doi.org/10.1016/j.jhazmat.2010.11.089

[12] Guidelines for the Management of Spent Catalysts. http://www.cefic.org/Documents/Industry\%20sectors/ECMA/ECMA\%20GUIDELINES\%2 0FOR\%20THE\%20MANAGEMENT\%20OF\%20SPENT\%20CATALYSTS-201202.pdf

[13] Ma, C.C. (2016) B2 Regeneration of Catalyst for Hydrogenation of Sugars. US Patent No. US 9427733. https://www.google.ch/patents/US9427733

[14] Chen, J.-C. and Huang, J.-J. (2013) Regeneration of Spent Catalysts by $\mathrm{H}_{2} \mathrm{O}_{2}$ Chemical Treatment. APCBEE Procedia, 5, 107-111. https://doi.org/10.1016/j.apcbee.2013.05.019

[15] Mousa, K.M. and Dawood, M.M. (2012) Experimental, Modelling and Kinetic Study for the Recovery of Molybdenum from Spent $\left(\mathrm{Ni}-\mathrm{Mo} / \mathrm{Al}_{2} \mathrm{O}_{3}\right)$ Catalyst of Hydrotreating Process. 20121 st National Conference for Engineering Sciences (FNCES 2012), Baghdad, 7-8 November 2012, 1-3. https://doi.org/10.1109/NCES.2012.6740466

[16] Ahmed, H.S. and Menoufy, M.F. (2012) New Trends in Hydroprocessing Spent Catalysts Utilization. In: Patel, V., Ed., Petrochemicals, InTech. Rijeka, 328 p.

http://www.intechopen.com.sci-hub.cc/books/petrochemicals/reuse-and-treatment-of-hydr otreating-spent-catalyst

[17] Liang, D.T. (2004) Management of Spent Catalysts in Petroleum Refineries. 2nd Asian Petroleum Technology Symposium Program, 2004. https://scribd.com/doc/6925147/MANAGEMENT-OF-SPENT-CATALYSTS-IN-PETROL EUM-REFINERIES

[18] European Catalyst Manufacturers Association (ECMA) (2008) Reach and Catalysts (Fresh and Spent).

http://www.cefic.org/Documents/Industry\%20sectors/ECMA/ECMA-position-paper-on-R EACH-and-catalysts-2012\%2005.pdf

[19] The Report "Catalyst Regeneration Market by Technology (Off-Site Regeneration and OnSite Regeneration). By Application (Refinery, Chemicals \& Petrochemicals, and Others), by Region (North America, Europe, Asia-Pacific, and Rest of the World), Forecast till 2019. Report Code: CH 2752.

http://www.marketsandmarkets.com/PressReleases/catalyst-regeneration.asp

[20] Rasmussen, S.B., Kustov, A., Due-Hansen, J., Siret, B., Tabaries, F. and Fehrmann, R. (2006) Characterization and Regeneration of Pt-Catalysts Deactivated in Municipal Waste Flue Gas. Applied Catalysis B: Environmental, 69, 10-16. https://doi.org/10.1016/j.apcatb.2006.05.009

[21] Dufresne, P. (2007) Hydroprocessing Catalysts Regeneration and Recycling. Applied Catalysis A: General, 322, 67-75. https://doi.org/10.1016/j.apcata.2007.01.013

[22] Argyle, M.D. and Bartholomew, C.H. (2015) Heterogeneous Catalyst Deactivation and Regeneration: A Review. Catalysts, 5, 145-269. https://doi.org/10.3390/catal5010145

[23] McMahon, B. (2006) Catalyst Regeneration: The Business Case. Power, 150, 36-39.

[24] Surinder, P. (2003) Refining Processes Handbook. Gulf Professional Publishing, Houston, $688 \mathrm{p}$.

[25] Chen, J. and Liu, C. (2013) Regeneration of Spent Catalysts with Ozone. World Academy of 
Science, Engineering and Technology, International Science Index 79. International Journal of Environmental, Chemical, Ecological, Geological and Geophysical Engineering, 7, 414417.

[26] Thi Chang Regeneration Industry Helps Refiners Control Costs, Limit Liabilities (1998). http://www.ogj.com/articles/print/volume-96/issue-41/in-this-issue/general-interest/regene ration-industry-helps-refiners-control-costs-limit-liabilities.html

[27] Janssen, F.J.J.G. and Rutger, A. (1999) Sante Environmental Catalysis. Imperial College Press, London, 369 p.

[28] Dufresne, P. and Locatelli, F. (2012) Decrease Catalyst Costs by Regeneration, Analysis and Sorting. Petroleum Technology Quarterly (PTQ): Refining, Gas Processing, Petrochemicals. Craven Arms [u.a.]: Crambeth Allen Publ, NUMB 1, SUPP, 45-52.

[29] Marafi, M. (2007) Antony Stanislaus Studies on Recycling and Utilization of Spent Catalysts: Preparation of Active Hydrodemetallization Catalyst Compositions from Spent Residue Hydroprocessing Catalysts. Applied Catalysis B: Environmental, 71, 199-206. https://doi.org/10.1016/j.apcatb.2006.09.005

[30] Gumerov, F.M., Sabirzyanov, A.N. and Gumerova, G.I. (2007) Sub- and Supercritical Fluids in Polymer Processing. 2nd Edition, FAN, Kazan, 336 p.

[31] Hansen, C.M. (2007) Hansen Solubility Parameters: A User’s Handbook. 2nd Edition. CRC Press, Boca Raton, 205 p.

[32] Gupta, R.B. and Shim, J.J. (2007) Solubility in Supercritical Carbon Dioxide. CRC Press. Boca Raton, 909 p.

[33] Chernyshev, A.K., Gumerov, F.M., Tsvetinsky, G.N., Yarullin, R.S., Ivanov, S.V., Levin, B.V., Shafran, M.I., Zhilin, I.F., Beskov, A.G. and Chernyshev, K.A. (2013) Carbon Dioxide. Properties, Recovery (Production), Applications. Galleya-Print, Moscow, 903 p.

[34] Amirkhanov, D.G., Gumerov, F.M., Sagdeev, A.A. and Galimova, A.T. (2014) Solubility of Substances in Supercritical Fluid Media. Otechestvo, Kazan, 264 p.

[35] Popov, V.K. (2013) Physical and Chemical Processes in Supercritical Fluids and Functionalization of Materials. Report for PhD Thesis in Chemistry, MSU, 78 p.

[36] Bilalov, T.R. and Gumerov, F.M. (2011) The Manufacturing Processes and Catalyst Regeneration/Thermodynamic Basis of Production Processes and Regeneration of Palladium Catalysts Using Supercritical Carbon Dioxide. LAP LAMBERT Academic Publishing GmbH \& Co. KG., Dudweiler Landstraße, 153 p.

[37] Gumerov, F., Sagdeev, A., Gallyamov, R., Galimova, A. and Sagdeev, K. (2014) Regeneration of the Catalysts by Supercritical Fluid Extraction. International Journal of Analytical Mass Spectrometry and Chromatography, 2, 1-14. https://doi.org/10.4236/ijamsc.2014.21001

[38] Jaddoa, A., Bilalov, T., Gumerov, F., Gabitov, F. and Neindre, B. (2015) Regeneration of Nickel-Molybdenum Catalysts DN-3531 and Criterion 514 Used in Kerosene and Gas Oil Hydrotreating by Supercritical Carbon Dioxide Extraction. International Journal of Analytical Mass Spectrometry and Chromatography, 3, 37-46. https://doi.org/10.4236/ijamsc.2015.33005

[39] Zakharov, A.A., Jaddoa, A.A., Bilalov, T.R. and Gumerov, F.M. (2014) Syntesis of the Palladium Catalyst with the Supercritical $\mathrm{CO}_{2}$-Impregnation Method Realized in the Static Mode. International Journal of Analytical Mass Spectrometry and Chromatography, 2, 113 122. https://doi.org/10.4236/ijamsc.2014.24010 
Submit or recommend next manuscript to SCIRP and we will provide best service for you:

Accepting pre-submission inquiries through Email, Facebook, LinkedIn, Twitter, etc. A wide selection of journals (inclusive of 9 subjects, more than 200 journals)

Providing 24-hour high-quality service

User-friendly online submission system

Fair and swift peer-review system

Efficient typesetting and proofreading procedure

Display of the result of downloads and visits, as well as the number of cited articles

Maximum dissemination of your research work

Submit your manuscript at: http://papersubmission.scirp.org/

Or contactijamsc@scirp.org 